\title{
Pension plan governance and risk management: A Canadian perspective
}

Received: 20th January, 2005

\section{Caroline L. Helbronner}

is a partner in the Pensions and Employee Benefits and Taxation groups of the Toronto offices of Blake, Cassels \& Graydon LLP. She advises employers, financial institutions and consulting firms on issues arising in circumstances such as surplus and contribution holiday disputes, cross-border situations and corporate transactions. She also advises on matters relating to compliance. She writes and speaks on topics in the fields of pension and employees benefits.

Abstract This paper, which has a Canadian focus, reviews the principal legal and financial risks associated with the operation of a pension plan. The author demonstrates that appropriate pension plan governance is an important tool in minimising the exposure to legal liability and the associated financial risks. She goes on to conclude that a properly constructed governance process coupled with the performance of periodic governance audits should permit plan sponsors to identify potential sources of obligation. They can then deal with them before they result in financial cost to the plan sponsor and, possibly, its directors and senior management.

Keywords: pension plan governance; legal principles and regulatory perspective; risk management; governance audits; Canadian perspective

\section{What is pension plan governance?}

Pension plan governance may be viewed as the process by which a plan administrator and/or sponsor discharges its legal obligations with respect to a pension plan. The sources of those legal obligations include statute and common law concepts such as fiduciary duties, tort (especially the tort of negligence) and contractual obligations. From a legal perspective, good governance will reduce the risk to a plan administrator/sponsor of being subject to legal liability in connection with the maintenance of a pension plan.

\section{Legal framework for pension plan governance}

The Pensions Benefit Act (PBA) and the Pension Benefits Standards Act (PBSA) both generally impose primary legal responsibility for the administration and operation of employer-sponsored pension plans and their related pension funds on the employer that maintains the plan. In the case of a corporate employer, this will generally mean that ultimate legal responsibility for the administration of such a plan rests with the board of directors of the employer.

The provisions of the PBA in this regard are as follows. Subsection 22(1) of the PBA requires the administrator of a pension plan (ie the principal employer under the plan) to exercise 'the care, diligence and skill in the administration and investment of the pension fund that a person of ordinary prudence would exercise in dealing with the property of another person'. Subsection 22(2) of the PBA requires that, in the course of administering a pension plan and 
investing the plan assets, the

administrator use 'all relevant knowledge and skill that the administrator possesses or, by reason of the administrator's profession, business or calling, ought to possess'. Subsection 22(4) states that the administrator of a pension plan cannot 'knowingly permit the administrator's interest to conflict with the administrator's duties and powers in respect of the pension fund'.

The reference in subsection 22(2) of the PBA to the administrator using all relevant knowledge or skills that it possesses or ought to possess may impose a higher duty on more sophisticated entities who have, or by reason of their profession or business ought to have, certain knowledge and skills that are pertinent to the administration of a pension plan and/or the investment of a pension fund. Also, an argument can be made that, simply as a result of being the administrator of a pension plan and being responsible for investing the assets of the plan, a person should be presumed to have certain relevant knowledge and skills, which such person must exercise in connection with the plan and fund.

The relevant provisions of the PBSA are similar to those in the PBA. In this regard, subsection 8(4) of the PBSA requires the administrator of a pension plan (ie the principal employer under the plan) to exercise the degree of care in the administration of the pension plan that a person of ordinary prudence would exercise in dealing with the property of another person. Subsection 8(4.1) of the PBSA requires the administrator to invest the assets of the pension fund in accordance with the regulations and in a manner that a reasonable and prudent person would apply in respect of a portfolio of investments of a pension fund. The PBSA also requires in subsection 8(5) that, in the course of administering a pension plan and investing the plan assets, the administrator use all relevant knowledge and skills that the administrator possesses or, by reason of the administrator's profession or business, ought to possess. Finally, section 8 of the PBSA prohibits certain conflicts of interest that may arise in connection with the administration of a pension plan.

Over and above the statutory requirements referenced above, the sponsor/administrator of a pension plan may also be subject to general fiduciary duties under the common law with respect to the administration of the plan and the investment of the pension fund. Historically, the relationship between an employer and its employees was viewed by the courts as contractual and fiduciary duties were not seen to arise on either side. This has changed over time. For example, the courts have been prepared to find that employees may have fiduciary duties to their employers (typically in the context of access to and use of confidential information of the employer $^{1}$ ) and in Confederation Life, ${ }^{2}$ the court concluded that it was possible for an employer to have fiduciary obligations to its employees with respect to retirement arrangements (although the court found that such obligations did not arise under the facts before it in Confederation Life).

The decision in Confederation Life was based on the approach to determining whether a fiduciary duty exists that was approved by the Supreme Court of Canada in a number of cases. ${ }^{3}$

Specifically, the Supreme Court has held that fiduciary duties may arise whenever one party has an obligation to act for the benefit of another, that obligation carries with it a discretionary power and the other party is particularly vulnerable to the exercise of such discretionary power. ${ }^{3}$ Consequently, although the Canadian 
courts have, to date, tended to rely on other legal principles than fiduciary duty to impose liability on pension plan administrators/sponsors with respect to the operation of a pension plan or fund, it is likely that many plan sponsors will

have some fiduciary responsibility under the common law in addition to their express statutory obligations. ${ }^{4}$

Basic fiduciary duties include:

- A duty to act reasonably and prudently.

- A duty of loyalty to those persons whose interests the fiduciary is protecting. A fiduciary cannot take into account considerations other than the best interests of those persons.

- A fiduciary must not let his personal interest conflict with his duty.

- A duty not to profit from the fiduciary's position and to account for any undisclosed profit.

- A duty to hold an 'even hand' between competing interests of those on whose behalf the fiduciary is acting.

Plan administration and investment matters that will typically be considered to fall within the fiduciary obligations of the entity responsible for the administration and operation of the plan include the investment of plan assets (this includes developing and implementing an appropriate investment policy), the calculation and paying of correct benefit payments, the proper remittance of contributions (ie in the correct amounts and within the time required), the appropriate communications to plan members and compliance with applicable law and the terms of the plan.

The nature of these potential duties and the extent of the likely risk to the sponsor/administrator with respect to any particular duty will generally differ somewhat depending on the plan type.
For example, if the pension plan is a money purchase plan under which members direct the investment of all amounts contributed to their accounts, the sponsor/administrator may be more at risk for claims relating, inter alia, to the provision of investment advice which turns out to be inaccurate, incomplete or otherwise inappropriate for the member to whom it is provided, the failure to inform and educate members about the investment options under the plan and investment principles in general and the imprudent selection of investment options. In the case of a defined benefit (DB) pension plan, as members are generally not directly at risk as a result of the selection of investments, the plan sponsor/administrator is less likely to be subject to liability for breach of fiduciary duties relating to plan investment, provided those investments comply with applicable law and perform adequately having regard to the investment policy implemented by the sponsor/ administrator and general market conditions. The sponsor/administrator, however, may have more legal exposure with respect to the calculation and payment of benefits under the DB plan, communications to plan members regarding such benefits and the application of surplus assets.

The courts have been prepared to impose liability on plan administrators on the basis of negligence (especially with respect to communications that were found to be erroneous or incomplete and on which the plan member reasonably relied to their detriment). ${ }^{5}$ It is also possible for a plan sponsor/administrator to be liable for breach of contract with respect to the administration of a pension plan to the extent that the plan is not administered in accordance with its terms. It should be noted in this regard that, while for the most part the terms of a pension plan will be found in the plan 
text and funding agreement that provides for the holding and investment of the plan assets, the courts have recognised that employee booklets and other communications from an employer to employees may 'form part of the legal matrix within which the rights of employers and employees participating in a pension plan must be determined.'

The doctrine of contra proferentem, which provides that, as a general rule, ambiguities in a document should be construed against the interests of the person who drafted the document, may also be relevant as, in most employer-sponsored pension plans, it is the employer and persons retained by the employer who are responsible for drafting plan documents and member communications about the plan.

\section{Principles of plan governance - The regulators' perspective}

Although, as highlighted above, the relevant statutes and the common law do impose certain duties on the administrator of a pension plan with respect to the operation of the plan that are relevant to the establishment and implementation of a pension governance policy, the scope and specific requirements of an appropriate pension plan governance process are not comprehensively codified in any statute.

In 1998, the Office of the Superintendent of Financial Institutions (OSFI) produced the 'Guideline for Governance for Federally Regulated Pension Plans'. While this guideline was specifically targeted at federally regulated plans, the general duties imposed on plan administrators under provincial pension standards legislation such as the PBA are similar in many respects to the corresponding duties under the PBSA. Consequently, the OSFI guideline provided some insight into plan governance for sponsors/administrators of both federally and provincially regulated plans. According to the OSFI guideline, the following principles underline good governance of pension plans:

- Clearly stated objectives.

- Independence of the governing body from the plan sponsor(s).

- Separation of governance from operations, clearly defined roles and responsibilities.

- Accountability and internal controls.

- Adequate knowledge and skill sets.

- Due diligence in decisions and supervision of delegated work.

- Controls for expenses and protection from conflicts of interest.

- Transparency and full disclosure.

The OSFI guideline also stressed the need to review governance continuously to meet emerging challenges.

OSFI again commented on plan governance in a PBSA Update which was issued in summer 2000. This update built to a large extent on the 1998 guideline. The update enumerated the following six governance principles:

- Pension plans should have a clear mission statement.

- Pension plans have a primary fiduciary duty to plan beneficiaries.

- Responsibilities and accountabilities should be allocated clearly.

- Performance should be measured and reported.

- Plan administrator should be qualified and knowledgeable.

- Governance self-assessment.

The update also notes that administrators of defined contribution (DC) plans must practice good governance as well.

Responsibilities imposed on the sponsor in the DC context are stated to include the selection of investment options 
offered, the disclosure of investment performance of the options selected and an education and communication programme for members. Finally, the update makes provision for a self-assessment tool for plan administrators.

Building, to some extent, on the OSFI guideline and on input from industry groups, the Canadian Association of Pension Supervisory Authorities (CAPSA), a national inter-jurisdictional association of pension supervisory authorities, has developed a governance guideline that is intended to reflect the collective views of all Canadian pension regulatory authorities on plan governance. A first draft of the CAPSA Guidelines was released in 2001. Following industry consultation, CAPSA then proceeded to work with an industry task force to assist in the development of an implementation tool and to assist in finalising both the governance principles and guidelines. In 2003, CAPSA released revised draft guidelines and a draft governance self-assessment questionnaire. CAPSA then proceeded to 'road test' the draft guidelines and questionnaire with administrators of all types and sizes of plans. Following the road-testing exercise, CAPSA finalised the guidelines and the questionnaire in the fall of 2004. It should be noted that the OECD published Guidelines for Pension Fund Governance in July 2002 which commented favourably on the CAPSA initiative.

The CAPSA guidelines set forth the following eleven governance principles.

- Fiduciary responsibility: The plan administrator has fiduciary and other responsibilities to plan members and other beneficiaries and may have similar responsibilities to other stakeholders.

- Governance objectives: The plan administrator should establish governance objectives for the oversight, management and administration of the plan.

- Roles and responsibilities: Roles, responsibilities and accountabilities of all participants in the pension plan governance process must be clearly delineated and documented.

- Performance measures: Performance measures for monitoring the performance of decision makers in the governance process should be established.

- Knowledge and skills: The plan administrator, either personally or through its delegates, has a duty to apply the knowledge and skills necessary to fulfil its governance responsibilities.

- Access to information: The plan administrator and its delegates should receive appropriate, timely and accurate information.

- Transparency and accountability: A communication policy directed at plan members, beneficiaries and other stakeholders should be established to facilitate transparency and accountability in the governance process.

- Code of conduct and conflict of interest policy: A code of conduct and a conflict of interest policy, including a process for resolving conflicts relating to pension plan administration issues, should be established.

- Risk management: An appropriate internal control framework should be established to address the pension plan's potential risk.

- Oversight and compliance: Appropriate mechanisms to facilitate oversight and ensure compliance with applicable laws, pension plan documents and administrative polices relating to the pension plan should be implemented.

- Governance review: Governance practices should be reviewed regularly 
and revised as necessary to ensure ongoing effectiveness.

The CAPSA governance principles have been presented as a best practices guideline, not law. CAPSA has indicated, however, that it 'expects that pension plan administrators will voluntarily take measures necessary to follow the guidelines'. Further, applicable industry standards will often influence a court in determining whether a particular course of conduct should attract liability.

Consequently, the extent of compliance (or non-compliance) by a plan sponsor or administrator with governance guidelines issued by pension and other regulatory bodies may well be taken into account by a court in determining whether the sponsor or administrator has met its statutory or common law obligations with respect to the plan. In any case, the guidelines will assist plan administrators in the development and maintenance of a sound governance structure.

Finally, reference should be made to '20 Questions directors should ask about their role in pension governance', a publication released by the Canadian Institute of Chartered Accountants ${ }^{7}$. In the course of its commentary on the topic of pension governance, this publication makes reference to a number of principles outlined above. In addition, it makes reference to a number of topics that should be covered by a plan sponsor when conducting a plan governance audit, a topic which is dealt with later in this paper.

\section{Principles of plan governance for sponsors/administrators}

When the collective commentary on this issue is considered, it would seem that the following governance principles have relatively broad general acceptance. ${ }^{8}$

\section{Roles, responsibilities and accountabilities of all participants in the governance structure need to be clearly identified and documented}

The board of directors of the employer under the plan, as the entity with ultimate legal responsibility for the proper administration of the plan, should approve the documented structure. The actual process of identifying and documenting roles, responsibilities and accountabilities may be performed by a pension committee of the board, a mixed committee of board and management or by management, depending on the corporate structure of the plan administrator. It is important that the persons charged with the responsibility for this process have sufficient understanding of key pension administration obligations, the capacity of the employer to perform those obligations and the resources available to identify and clearly document all relevant roles, responsibilities and accountabilities.

The governing body (in a plan sponsored by a corporation, the board of directors) in its capacity as plan administrator and its delegates have fiduciary duties to plan members and beneficiaries

As noted above, this would include a requirement to act in the best interests of the plan members and other beneficiaries and not allow personal interests to conflict with the duty to members and other beneficiaries.

Where an entity is both the administrator of a pension plan and the employer under the plan, the general view is that the entity will have fiduciary duties to members and other plan beneficiaries in its capacity as plan administrator, but not in its capacity as 
employer. It is, therefore, important to carefully delineate plan administrator responsibilities and plan sponsor functions. Some areas where this is particularly important include: the establishment of an investment policy (generally an administrator function); the payment by the sponsor of expenses directly out of the plan funds (as a plan design issue, this is an employer function, but in interpreting the plan and actually authorising the payments, it will probably be an administrator function); ownership of surplus (generally, the issue will be whether the employer owns surplus in its personal capacity, but the payment of surplus out of a plan or other application of surplus may be made by the administrator); plan mergers and conversions (as in the case of the payment of expenses, as a plan design issue, these will generally be employer functions, but implementation of a merger or conversion will probably be carried out by the administrator), funding and accounting policies (these latter two items are generally viewed as employer functions unless the plan documentation provides otherwise).

\section{The governing body and its delegates should, collectively, have the appropriate skills and experience required to fulfill their fiduciary and other responsibilities with respect to the administration of the plan}

Where appropriate, the governing body should seek information and advice from qualified external advisors and may delegate responsibilities to other individuals with the required skill sets and resources available to discharge those tasks. A governance policy may wish to encourage delegation where the requisite expertise and/or resources are not available within the plan administrator's own organisation.

\section{Members of the governing body should be provided with appropriate training and undertake ongoing education}

An entity charged with fiduciary and other responsibilities in connection with the administration and operation of a plan needs to have the time and resources to acquire the knowledge and skills required to make appropriate informed decisions or at least to determine where retention of external resources and delegation are appropriate. This should be expressly documented in the plan governance policy and should apply not only to the ultimate governing body, but also to committees and employees within the plan administrator's organisation who will have responsibilities relating to the administration of the plan and/or the investment of plan assets.

\section{The governing body should receive appropriate, timely and accurate information}

This means that the board of directors of the employer that administers a pension plan should receive accurate and complete information concerning the operation and administration of the plan on a periodic basis from individuals and committees within their own organisation and from third parties retained by the administrator to assist it with the administration of the plan and/or the investment of plan assets. This may entail building into contracts the third party requirements to report to an appropriate person or committee in the plan administrator's organisation, audit rights for the plan administrator and its chosen auditors and enforcement mechanisms where the third party fails to meet its disclosure obligations. It is important to remember in this context that the governing body retains ultimate 
responsibility for monitoring and oversight of its delegates.

\section{A code of conduct and control mechanism for conflicts of interest should be established}

Such a code of conduct should be in writing and not only identify the situations in which conflicts may arise, but also set out required behaviour to (a) limit the likelihood of conflicts occurring; and (b) establish a mechanism for reporting and otherwise resolving conflicts. In many circumstances, it will be appropriate to require third parties retained by the plan administrator to adhere to the plan administrator's conflict of interest policy.

\section{An appropriate internal control framework should be maintained}

There should be appropriate controls in place to ensure that all persons and entities with operational and oversight responsibilities act in accordance with the governance mandate. Such controls should cover all basic organisational and administrative procedures.

Plan sponsors are advised to ensure that they have internal written policies that support the internal controls. For example, there should be clear written rules relating to plan funding strategies, asset management, investment manager selection, expensing, outsourcing of functions and selection of service providers and professional advisors.

\section{The governing body should have appropriate mechanisms in place to oversee the administration of the plan and to ensure compliance with legislative requirements}

This is particularly relevant for registered pension plans in view of the fact that they are subject to more detailed compliance legislation than other types of employee plans. This will generally require the implementation of regular reports from those who are involved in day to day plan administration to more senior management (generally, with human resources and/or finance responsibilities, depending on the subject matter of the reports) and from management to the board of directors or a committee of the board of directors. As noted above, third party service providers should also be required to report regularly to the plan administrator.

Effective oversight requires that, not only is there an appropriate reporting structure in place and reports are made, but also that the higher level body reviews the reports with care and identifies potential concerns with the content, form and timing of the reported information.

\section{Objective performance measures for decision makers and service providers and plan performance should be established}

It is generally recommended that objective performance measures be established by the plan administrator for all key decision makers and delegates (both internal and external), including employees of the plan sponsor who provide services to the plans, custodians, trustees, investment managers, third party benefit administrators and professional service providers/professional advisors. In addition to actually reviewing those persons' performance against the applicable performance measures, they should be reviewed by the plan administrator periodically to ensure they remain appropriate. Third party assistance may be required to design and update appropriate performance measures, as many plan sponsors will not have the internal expertise to establish such 
measures for all of the persons involved in the administration of a pension plan and the investment of plan assets.

\section{Governance practices should be reviewed regularly and existing practices modified as appropriate}

The governing body of a plan should periodically review the plan governance procedures in place to ensure that they are operating properly. This self-assessment process would typically involve a committee or certain specific individuals within the plan sponsor organisation with significant responsibility for plan administration reporting to the ultimate governing body (ie in a corporation, the board of directors or a committee of the board of directors).

\section{Pension plan governance audits}

Pension plan governance audits are an important element of good overall pension plan governance. Governance audits are a tool used to ensure that the pension governance structure which has been implemented is being properly administered.

This section of the paper is intended to provide the reader with an overview of the basics of pension plan governance audits. It is not an exhaustive review of every aspect of governance audits, since each pension plan will have its own unique characteristics and circumstances that may impact on why, how and when a governance audit should be performed. Rather, it will explain the general issues that a plan sponsor or administrator needs to consider in relation to pension plan governance audits.

\section{What is a governance audit?}

A governance audit is an independent review of a pension plan's:
- governing documents;

- operating procedures and practices;

- delegation of the administrator's duties and responsibilities;

— investment management structure;

- service provider services; and

- documentation procedures.

The audit is intended to determine whether the plan documents comply with applicable law and whether the plan is being administered in accordance with its terms, applicable law and the directions and intentions of the plan sponsor. A governance audit is also designed to ensure that all plan administration activities are properly documented.

Special governance audits may also be appropriate to review particular circumstances, such as:

- the conversion of the plan from DB to DC or vice versa;

- a partial plan wind-up;

- a plan merger; or

- the insolvency of the plan sponsor.

\section{Why do a governance audit?}

A governance audit serves the following three general purposes:

- to improve the overall administration of the plan;

- to ensure legal compliance, including compliance with the following:

(i) fiduciary obligations of the administrator;

(ii) minimum standards requirements; and

(iii) reporting obligations; and

- to minimise the risk of legal claims against the fund, the sponsor/ administrator, its officers and directors and other related entities (eg funding agent, service providers, etc). 
Improving plan administration

Regular governance audits of a pension plan conducted by an independent third party help improve the overall administration of the plan in a number of ways. First, any problems with the way in which the plan is being administered or with any legal compliance issue can be quickly identified and appropriate steps can immediately be taken to remedy the problems.

Secondly, a governance audit forces the plan administrator to examine or re-examine plan administration issues which are raised during the course of the audit and which may otherwise not be brought to the attention of the administrator. For example, the audit may determine that the individuals who are responsible for the day to day administration of the plan require a more thorough understanding of the plan's terms, which is something that the administrator itself may be unable to determine without the assistance of a review by an independent third party.

Thirdly, a governance audit allows for a 'fresh set of eyes' (ie the independent auditor) to review how the plan is being administered and suggest new or alternative ways of dealing with certain administrative issues. An advantage of having an independent auditor review the administration of the plan is that the auditor will not be wedded to current administrative practices, which would probably be the case if the review was performed by the individuals who are currently responsible for the administration of the plan.

\section{Legal compliance}

One of the most important reasons for having a governance audit performed is to ensure compliance with the various legal requirements imposed on a plan and the administrator.

\section{Administrator's fiduciary duties}

One means by which a plan administrator can attempt to adhere to this duty, at least in part, is to arrange periodic independent reviews (ie audits) of the plan's documents and the manner in which the plan is being administered.

\section{Minimum standards compliance}

A governance audit is also useful for ensuring that the plan documents, as well as the way in which the plan is being administered, comply with minimum standards legislation. More specifically, the audit should include a review of the plan documents to ensure that they reflect all recent changes in minimum standards legislation. A governance audit should note any amendments to the plan documents that are required to ensure continued compliance with applicable legislation.

In addition, minimum standards compliance includes ensuring that the plan is being administered in accordance with its terms and applicable legislation. In this regard, the audit should include a review of all administrative duties for compliance with both the terms of the plan and minimum standards legislation. A few examples of such administrative duties include

- ensuring that contributions are made within the time frames set out in the plan and under applicable legislation;

- terminating or retiring members are provided with the portability options specified in the plan;

- forms used by the administrator (eg spousal wavier forms) comply with minimum standards legislation, etc.

A governance audit should ensure that duties and responsibilities delegated by the plan administrator (either externally to professional service providers or internally to employees of the 
sponsor/administrator) comply with the requirements that such delegation is 'reasonable and prudent' in the circumstances and that those to whom the duties and responsibilities are delegated have the appropriate skills to perform the necessary tasks. It should also ensure that the plan administrator's monitoring of those to whom duties and responsibilities have been delegated is reasonable and prudent.

\section{Reporting obligations}

A governance audit should ensure that all plan-related reports comply with the requirements of minimum standards legislation. For example, the audit should review the information provided to plan members (eg annual benefit statements, termination statements, etc), documents required to be filed with the applicable regulators (eg annual information returns, actuarial valuation reports, etc), the plan documents which are made available to plan members for inspection, and other reporting activities to which minimum standards legislation apply, to ensure that the applicable minimum standards are being satisfied.

\section{Minimising legal risks}

By conducting regular governance audits of a pension plan, errors or other problems with the manner in which the plan is being administered are much more likely to be identified at an early stage. Such early detection will often allow the plan administrator to take the necessary steps to correct the problem before it results in a legal claim against the fund, the sponsor/administrator, its officers and directors or other persons involved in the administration of the plan.

By performing regular governance audits of the pension plan, the potential liability of officers and directors of the sponsor/administrator is minimised by reducing the likelihood of claims through early detection and correction of problems with the administration of the plan. Also, in respect of any claims relating to problems with the administration of the plan that were not identified in the audit report and which were not otherwise brought to the attention of the officers and directors of the plan sponsor/administrator, the officers and directors would have a much stronger argument that they satisfied their obligation to take reasonable care to prevent a contravention of the applicable pension legislation and its regulations by having the audit performed.

\section{Who should perform the audit?}

A governance audit focuses on the actual administration, decision making and procedural aspects of the plan's operation. As such, an outside, independent third party should perform the audit. An actuarial or management consultant is the most appropriate party to conduct the audit, although review by in-house or external legal counsel is strongly recommended.

The reason for having the audit reviewed by legal counsel is twofold. First, legal counsel (especially counsel with pension law experience) can add value by confirming whether the legal compliance issues discussed above have been satisfied. Secondly, by having the audit report prepared for legal counsel to review, there will be a stronger argument for maintaining the confidentiality of the report on the basis of solicitor-client privilege in the event of future litigation regarding the administration of the plan. Specifically, in order to best protect a claim of solicitor-client privilege over the audit report, the plan sponsor should arrange for its legal counsel to directly retain the consultant to conduct the audit and prepare the audit report. The issue 
of the disclosure of the audit report is discussed in more detail below.

As noted above, an advantage of having an outside independent party conduct the audit, rather than an employee of the plan administrator, is that an independent party is not wedded to past administrative practices and is able to bring a fresh set of eyes to plan administration issues. Another advantage is that the findings of an independent auditor are likely to have considerably more credibility with pension regulators and plan members in the event of a future dispute regarding the practices and procedures of the administrator.

Plan sponsors and administrators should also be aware that applicable pension regulators have the authority to conduct random audits of a pension plan.

\section{What should the governance audit cover?}

Minimum standards legislation does not require governance audits of a plan to be performed. As a result, there are no statutory requirements setting out what an audit should cover or how an audit is to be performed.

The following is a list of the most significant issues that should be addressed by a governance audit. Many of the following points are highlighted in the publication '20 Questions directors should ask about their role in pension governance'? ${ }^{\text {? }}$

- First and foremost, a governance audit should include a full review of all plan documents. It is surprising how many plan administration problems that arise could have been avoided by simply amending a plan provision to clarify the intention of the plan sponsor/administrator.

- The audit should also include a review of the form and content of all disclosure and communication materials which are provided to plan members. In many cases, pension litigation involves circumstances in which the information provided to plan members was inconsistent with the terms of the plan. For example, plan administration problems often occur where plan member booklets contain descriptions and/or investment information that is inconsistent with actual plan practices. Amending such booklets is a relatively simple undertaking that may avoid serious problems in the future.

- Another important aspect of a governance audit is a review of the various regulatory filings that the administrator is required to provide under minimum standards legislation, including a review of the following:

(i) plan amendments and the corresponding regulatory filing forms;

(ii) annual information returns;

(iii) actuarial valuations and cost certificates;

(iv) audited financial statements; and

(v) board of directors' resolutions and approvals relating to the administration of the plan.

- The audit should also include a review of the Statement of Investment Policies and Procedures (SIP\&P) for the plan, ensuring that it complies with the requirements of minimum standards legislation (including compliance with the requirement that the SIP\&P be reviewed at least annually) and that it accurately reflects the investment objectives of the fund. The audit should also ensure that the investment managers are aware of the requirements of the SIP\&P and are promptly notified of any changes thereto.

— In addition to a review of the SIP\&P, 
the audit should specifically review the investment of the plan assets. For example, the audit should review the following issues:

(i) Does the plan have a cost-effective audit programme in place?

(ii) Are contributions to the plan invested as soon as possible?

(iii) How are the investment managers and/or investment options chosen and monitored?

(iv) Are procedures in place for ensuring that the plan's investment objectives are understood by the investment managers and that such objectives are properly carried out?

(v) How are new investment managers and/or options added and existing ones removed?

In the case of a DC plan, the overall performance of employees' investment should be monitored.

- A governance audit should include a review of the funding policies and financial reporting practices for the plan.

- A governance audit should examine the manner in which benefits are processed. This includes a review of whether benefits are being paid in accordance with the terms of the plan and whether the individuals who make these decisions are properly trained and supervised.

- The audit should review the delegation of the administrator's duties and responsibilities to ensure such delegation is reasonable and prudent, including the manner in which the administrator supervises and monitors those to whom it delegates any of its duties and responsibilities.

- The audit should specifically review the contracts and performance of any external service providers to determine whether:

(i) they are operating under reasonable contracts;

(ii) they are paid reasonable compensation; and

(iii) their work is sufficiently monitored.

- A governance audit should review all administrative expenses which are being charged to the plan to determine if they are reasonable and defensible in light of all facts and circumstances. If the plan is a DC plan, fees paid by members should be reviewed to ensure that they are competitive.

- The audit should also focus on any special problems or concerns that may have arisen. For example, are there any threatened or filed lawsuits which could merit further inquiry? Is there a funding deficiency? Are there any other red flags that should be looked into?

- Finally, the audit should examine whether the issues discussed above have been properly documented. Next to failing to follow the provisions of the plan, poor documentation procedures are probably the cause of the most problems for plan administrators.

\section{What kind of problems might be found?}

The following are the most common types of problems uncovered by a governance audit:

— benefits processing issues (eg misinterpreting the plan terms, records protection and retention, etc);

- improperly documenting plan administration procedures;

— ineligible expenses being paid from the plan; 
- confusion regarding the role of plan administrator and plan sponsor;

- membership eligibility issues;

- member communication material is out-of-date;

— funding issues;

— investment issues (eg performance measurement, manager selection and supervision, out-of-date SIP\&P, etc);

- the plan terms and/or plan administration are inconsistent with the terms of applicable collective agreements; and

- out-of-date or unreasonable contracts with service providers.

\section{What if problems are found?}

Since pension governance audits are not statutorily required, there is no requirement to have a written audit report prepared. A plan administrator should not first learn of a serious plan administration problem through a written audit report. Any problems which are uncovered by the audit, as well as appropriate solutions, should be discussed and agreed upon so that, if a written report is prepared, it will contain the solution together with a description of the problem. In most cases, compliance can be achieved by prospective changes to a plan's practices and procedures, greater attention to proper documentation and monitoring and, in some cases, selective plan amendments.

Provided that the cost of the audit and the preparation of the report are paid by the plan sponsor directly and not out of the plan assets, the report should not constitute plan property. As such, there is a strong argument that an audit report which is paid for by the sponsor need not be disclosed to the plan members.

The fact that the audit report need not be disclosed to plan members does not obviate the administrator's fiduciary duty to the beneficiaries of the plan. In other words, a plan administrator cannot 'stick its head in the sand' and pretend that the problems raised by the audit do not exist. The administrator will be required to take all necessary steps to correct any such problems and ensure the continued compliance of the plan with applicable legislation.

If the audit is paid for out of the plan, there is a much stronger argument that the audit report is plan property and that the findings of the report should be disclosed to the beneficiaries of the plan. The advantage of the plan sponsor paying the cost of the audit is that the sponsor is more likely to have an opportunity to determine an appropriate solution to any problems revealed by the audit and be in a position to explain the proposed solutions as part of the written audit report. This allows the plan sponsor to be pro-active in correcting plan administration problems, rather than dealing with such problems defensively.

\section{The bottom line - Pension governance and risk management}

There are legal and financial risks associated with the operation of a pension plan. Some of the main legal risks are discussed above, but to summarise, the legal risks arise because legislation and the common law impose various duties on employers who choose to sponsor pension plans. Failure to perform those duties with the appropriate degree of care will expose the plan sponsor to the risk of being required to make financial reparations or take other steps to compensate those individuals and other entities who have suffered losses as a result of the plan sponsor's failure.

Appropriate pension plan governance is an important tool in minimising the 
exposure to legal liability and the associated financial risks. Establishing and implementing a reasonable pension plan governance policy will not completely insulate a plan sponsor from such liability. The absence of such a policy or the failure to implement such a policy, however, is likely to be a factor that will encourage a court to find against a plan sponsor.

Furthermore, as suggested above, a properly constructed governance process coupled with the performance of periodic governance audits should permit plan sponsors to identify potential sources of obligation and deal with them before they result in financial cost to the plan sponsor and possibly its directors and senior management.

\section{Acknowledgment}

Caroline gratefully acknowledges the assistance of her partners, Elizabeth Boyd and Jeffrey Sommers, in the preparation of this paper.

(C) Caroline Helbronner

\section{References}

1 See, for example, Canadian Aero Service Ltd $v$ O’Malley, [1974] SCR 592.

2 Canada (Attorney General) v Confederation Life Insurance Company (1995) 24 OR (3d) 717 (Gen Div) at 763 (affirmed, Ont CA, (1997), 32 OR (3d) 102).

3 See, for example, Guerin v The Queen, [1984] 2 SCR 335; Hodgkinson v Simms, [1994] 3 SCR 377.

4 Cases in which a fiduciary duty has been recognised include: $R$ v. Enfield (1995) 129 DLR (4th) 367 (Ont Ct, Gen Div); Anova Inc. Employee Retirement Pension Plan (Administrator of) v Manufacturers Life Insurance Co. (1994), 121 DLR (4th) 162 (Ont Ct, Gen Div); Re Imperial Oil Retirement Plan (No. 2) (3 August 1995) (Pension Commission of Ontario); Froese v. Montreal Trust Co. of Canada (1996), 137 DLR (4th) 725 (BCCA).

5 See, for example, Bratkowski v Ontario Teachers' Pension Plan Board (1997), 16 CCPB 182 (Ont Ct, (Gen Div), Spinks v Canada (1996), 12 CCPB 81 (FCA) and Deraps $v$ Trustees of the Labourer' Pension Fund (1999), 21 CCPB 304 (Ont CA).

6 Schmidt $v$ Air Products of Canada Ltd. (1994), 115 DLR (4th) 631 (SCC).

7 Hall, G. M. (2003) '20 Questions directors should ask about their role in pension governance', The Canadian Institute of Chartered Accountants, Toronto, Canada.

8 Variations from at least some of these principles may be justified, or even required, by particular features of a pension plan, or particular circumstances applicable to the plan, its members and/or the sponsor or administrator. 